Original Article

\title{
FORMULATION AND EVALUATION OF MOISTURIZING CREAM CONTAINING SUNFLOWER WAX
}

\author{
AVISH D. MARU' ${ }^{*}$, SWAROOP R. LAHOTI² \\ ${ }^{1 *}$ Research Scholar, Department of Pharmaceutics, Maulana Azad Educational Trust's Y. B. Chavan College of Pharmacy, Aurangabad, MS, \\ India, 'Professor and Head, Department of Pharmaceutics, Maulana Azad Educational Trust's Y. B. Chavan College of Pharmacy, \\ Aurangabad, MS, India \\ Email: avish.maru@gmail.com
}

Received: 20 Jul 2018 Revised and Accepted: 05 Oct 2018

ABSTRACT
Objective: The main objective of the present investigation was to design, prepare and evaluate moisturizing cream using sunflower wax.

Methods: In the present work $3^{2}$ full factorial design was applied to study the effect of varying concentration of independent variables stearic acid (X1) and sunflower wax (X2) on dependent variables viscosity and spreadability. All of the prepared formulations of moisturizing cream were evaluated for its physicochemical parameters. Further, the optimized formulation and selected commercial moisturizer compared and evaluated for its physicochemical parameters like $\mathrm{pH}$, particle size, spreadability, viscosity and in vitro occlusivity test.

Results: Nine different formulations of the moisturizing cream were prepared and all the findings obtained were within the prescribed limit. When compared to the prototype formulation of cream, the formulation MF5 showed good viscosity, in vitro occlusivity and spreadability. From the nine different formulations, MF5 containing $2 \%$ stearic acid and $2 \%$ sunflower was chosen as the optimized formula. Optimization was done on the basis of in vitro occlusivity studies and physicochemical parameters.

Conclusion: The results obtained in this research work clearly showed a promising potential of moisturizing cream containing a specific ratio of stearic acid and sunflower wax as emulsifiers. Thus it can be concluded that sunflower wax is incorporated in the moisturizing cream, to avail of its cosmetic benefits.

Keywords: Moisturizing cream, Sunflower wax, In vitro occlusivity, Spreadability

(C) 2018 The Authors. Published by Innovare Academic Sciences Pvt Ltd. This is an open-access article under the CC BY license (http://creativecommons.org/licenses/by/4.0/]

DOI: http://dx.doi.org/10.22159/ijpps.2018v10i11.28645

\section{INTRODUCTION}

The appearance and function of the skin are maintained by an important balance between the water content of the stratum corneum and skin surface lipids [1-2]. The skin represents the most superficial layer of the body, and so it is constantly exposed to different environmental stimuli [3]. Exposure to external factors as well as endogenous factors may disrupt this balance [4-6]. In addition, frequent use of soaps, detergents and topical irritants such as alcohol and hot water can remove the skin surface lipids [7] Disruption of skin barrier led to the various type of skin problems most common condition is a loss of water content which leads to dryness of skin such as roughness, scaling, cracks, redness and an uncomfortable feeling of tightness, sometimes with itching and stinging [8]. Treatment with moisturizer aims at maintaining skin integrity and well-being by providing a healthy appearance of the individual. Numbers of moisturizers are available under the label of natural, safe, organic, herbal while the basic properties of humectancy, occlusivity and emolliency are consistent across all moisturizers [9]. Most of the available moisturizers use synthetic adhesives, emulsifiers, perfuming agents, pigments, surfactants and thickeners to form the base. There is extensive need to replace toxic synthetic agent from the base using natural agents [10-11].

Waxes from both animal and plant origin are esters of high molecular weight monohydroxy alcohols and high molecular weight carboxylic acids [12]. They are chemically different from fats and oils, from hydrocarbons or paraffin waxes and from synthetic polyether waxes such as carbowax. Carnauba wax, bees wax, candelilla wax are the natural waxes commonly used in cosmetic and pharmaceutical products. Sunflower wax is a hard, white crystalline, high melting point vegetable wax and is Ecocert certified [13-14]. It largely contains ceryl cerotate. It is also economical as compared to imported carnauba wax. It helps to thicken the formulation by providing a rigid structural network of wax crystals, improving oil binding, emolliency, film formation and lubricity. Sunflower wax can be a useful replacement for the carnauba, candelilla or mineral waxes particularly in lipsticks, mascara, balms, creams, lotions and other oil based formulations [1516]. Therefore, an attempt has been made in the present study to utilize sunflower wax substituting stearic acid with functional benefits. Our endeavour has been to formulate moisturizer with sunflower wax to evaluate its efficacy and safety parameters as compare to available commercial moisturizer.

\section{MATERIALS AND METHODS}

\section{Materials}

The sunflower wax was obtained as a gift sample from M/s. Mahesh India, Mumbai. Stearic acid, lanoline, glycerin, liquid paraffin, glyceryl monostearate, isopropyl myristate, triethanolamine and borax were used of analytical grade.

\section{Methods}

\section{Preparation of moisturizing cream}

In the preliminary stages of these studies, the objective was to manufacture a moisturizing cream formulation extemporaneously that showed no visible signs of physical instability such as cracking creaming, phase inversion and/or bleeding of the cream base from the container. Physical instability was evaluated immediately after manufacture and then twenty-four (24) hours after manufacture and storage at room temperature $\left(25^{\circ} \mathrm{C}\right)$. Initial formulation development was undertaken on batches of only $25 \mathrm{~g}$ and any formulation that showed signs of physical instability immediately and/or after twentyfour (24) hours of storage at room temperature $\left(25{ }^{\circ} \mathrm{C}\right)$ was considered unsuitable and therefore not considered for further investigation. The formulation for the prototype moisturizing cream based on triethanolamine stearate as shown in table 1. Moisturizing cream formulation were developed from a prototype moisturizing 
cream formulation based on triethanolamine using stearic acid and sunflower wax alone and in combination of both. Oil in water emulsion cream was prepared by initially melting sunflower wax at $70-80{ }^{\circ} \mathrm{C}$ and to the molten mass added stearic acid, liquid paraffin, lanoline, glyceryl monostearate. Aqueous phase along with propylene glycol, isopropyl myristate, triethanolamine, glycerin and water heated at sametemperature as oil phase. Both the phases were mixed slowly with continuous stirring to form the homogenous dispersion. Perfume was added when the temperature downs at $35^{\circ} \mathrm{C}$. Preservatives added in the water phase before mixing [17].

Table 1: Prototype formula for moisturizing cream

\begin{tabular}{lll}
\hline S. No. & Ingredients & Quantity for 100 g (\%) \\
\hline & Oil Phase & \\
2 & Stearic acid & $4.0 \%$ \\
3 & Liquid paraffin & $8.0 \%$ \\
4 & Lanoline & $1.0 \%$ \\
& Glyceryl monostearate & $3.0 \%$ \\
5 & Water phase & \\
6 & Glycerin & $4.0 \%$ \\
7 & Propylene glycol & $4.0 \%$ \\
8 & Isopropyl myristate & $2.0 \%$ \\
9 & Triethanolamine & $0.2 \%$ \\
10 & Methyl paraben & $0.03 \%$ \\
11 & Propyl paraben & $0.07 \%$ \\
12 & Perfume & q. s. \\
\hline
\end{tabular}

\section{Formulation optimization}

In order to formulate moisturizing cream with sunflower wax, stearic acid was partially and completely replaced by it and also the triethanolamine as an emulsifying agent was replaced with borax to prepare a stabilized formulation. $3^{2}$ full factorial design was applied to the formulation that showed the satisfactory results to see the effect of varying the concentration of variables stearic acid (X1) and sunflower wax (X2) on responses like viscosity and spreadability. The levels of the two factors were selected on the basis of studies carried out before implementing the experimental design. Table 2 summarizes the experimental runs, their factor combinations and the translation of the coded levels to the experimental units used in the study. Composition of all prepared batches is mentioned in table 3 .

Table 2: Experimental runs for the formulations of moisturizing cream used in the study with coded values

\begin{tabular}{lllll}
\hline Independent variables & Name & Unit & \multicolumn{2}{l}{ Levels } \\
\cline { 3 - 5 } & & Low (-1) & Medium (0) & 2 \\
$X_{1}$ & Stearic acid & $\%$ & 1 & 4 \\
X2 & Sunflower wax & $\%$ & 1 & 2 \\
\hline
\end{tabular}

Table 3: Composition of all formulations of moisturizing cream

\begin{tabular}{|c|c|c|c|c|c|c|c|c|c|}
\hline \multirow[t]{2}{*}{ Ingredients (\%) } & \multicolumn{9}{|c|}{ Formulation codes } \\
\hline & MF1 & MF2 & MF3 & MF4 & MF5 & MF6 & MF7 & MF8 & MF9 \\
\hline Stearic acid & 1 & 1 & 1 & 2 & 2 & 2 & 4 & 4 & 4 \\
\hline Sunflower wax & 1 & 2 & 4 & 1 & 2 & 4 & 1 & 2 & 4 \\
\hline Liquid paraffin & 8.0 & 8.0 & 8.0 & 8.0 & 8.0 & 8.0 & 8.0 & 8.0 & 8.0 \\
\hline Lanoline & 1.0 & 1.0 & 1.0 & 1.0 & 1.0 & 1.0 & 1.0 & 1.0 & 1.0 \\
\hline Glyceryl monostearate & 3.0 & 3.0 & 3.0 & 3.0 & 3.0 & 3.0 & 3.0 & 3.0 & 3.0 \\
\hline Glycerin & 4.0 & 4.0 & 4.0 & 4.0 & 4.0 & 4.0 & 4.0 & 4.0 & 4.0 \\
\hline Propylene glycol & 4.0 & 4.0 & 4.0 & 4.0 & 4.0 & 4.0 & 4.0 & 4.0 & 4.0 \\
\hline Isopropyl myristate & 2.0 & 2.0 & 2.0 & 2.0 & 2.0 & 2.0 & 2.0 & 2.0 & 2.0 \\
\hline Borax & 0.2 & 0.2 & 0.2 & 0.2 & 0.2 & 0.2 & 0.2 & 0.2 & 0.2 \\
\hline Methyl paraben & 0.03 & 0.03 & 0.03 & 0.03 & 0.03 & 0.03 & 0.03 & 0.03 & 0.03 \\
\hline Propyl paraben & 0.07 & 0.07 & 0.07 & 0.07 & 0.07 & 0.07 & 0.07 & 0.07 & 0.07 \\
\hline Water to make & 100 & 100 & 100 & 100 & 100 & 100 & 100 & 100 & 100 \\
\hline Perfume & q. s. & q. s. & q.s. & q.s. & q. s. & q. s. & q. s. & q. s. & q. $s$. \\
\hline
\end{tabular}

\section{Evaluation of moisturizing cream}

Cream products were characterized by $\mathrm{pH}$, spreadability, viscosity, in vitro occlusivity and particle size [18-28].

\section{pH measurement}

The $\mathrm{pH}$ of the $10 \% \mathrm{w} / \mathrm{v}$ cream suspension was determined at $25{ }^{\circ} \mathrm{C}$ using a $\mathrm{pH}$ meter, standardized using $\mathrm{pH} 4.0$ and 7.0 standard buffers before use and average of triplicates were determined.

\section{Spreadability}

The spreadability of test samples was determined using the following technique: $0.5 \mathrm{~g}$ test formulation was placed within a circle of $1 \mathrm{~cm}$ diameter pre-marked on a glass plate over which a second glass plate was placed. A weight of $500 \mathrm{~g}$ was allowed to rest on the upper glass plate for $5 \mathrm{~min}$. Spreadability refers to the area covered by a fixed amount of cream sample after the uniform spread of sample on the glass slide. The increase in the diameter due to spreading of the test formulation was noted. Average of three determinations was noted.

\section{Viscosity}

Brookfield Synchro-Lectric Viscometer (Model RVT) with helipath stand was used for rheological studies. The sample (50 g) was placed in a beaker and was allowed to equilibrate for 5 min before measuring the dial reading using a T-D spindle at 10 , 
$20,30,50,60,100 \mathrm{rpm}$. At each speed, the corresponding dial reading on the viscometer was noted. The spindle speed was successively lowered and the corresponding dial reading was noted. The measurements were carried in triplicate at ambient temperature. Direct multiplication of the dial readings with factors given in the Brookfield viscometer catalogue gave the viscosity in centipoises. Average of three triplicates was computed.

\section{Thermal stability}

Thermal stability (at $20{ }^{\circ} \mathrm{C}, 30{ }^{\circ} \mathrm{C}$ and $40{ }^{\circ} \mathrm{C}$ ) of the prepared formulations was determined according to Indian standard guideline.

\section{In vitro occlusivity test}

Beakers of diameter $3.2 \mathrm{~cm}$ and height $4.6 \mathrm{~cm}$ were used. The test was performed by placing $10 \mathrm{~g}$ of distilled water in each beaker and closing the open end with Whatman filter paper ( 0.45 pore size) on the upper surface of which $200 \mathrm{mg}$ of the sample was evenly distributed. These beakers were then placed at $37 \pm 2{ }^{\circ} \mathrm{C} / 607 \pm 5 \% \mathrm{RH}$ for $48 \mathrm{~h}$. The samples of all formulations, prototype formulation and a negative control where the filter paper was kept uncovered were studied for the in vitro occlusivity to determine the water flux.

The occlusion factor $\mathrm{F}$ was calculated as

$$
F=\frac{(A-B)}{A} \times 100
$$

Where,

$A=$ Water flux through uncovered filter (percent water loss)

$\mathrm{B}=$ Water flux through filter when covered by test preparation (percent water loss)

\section{Measurement of particle size}

A laser diffraction particle size analyzer (Mastersizer Hydro $2000 \mathrm{MU}$ Malvern Instruments) was employed for measuring the globule size distribution of the emulsion droplets. Briefly, the sample was dispersed in 0.2 micron filtered distilled water to obtain an obscuration of 5-15\%.

\section{RESULTS AND DISCUSSION}

pH

$\mathrm{pH}$ of all the formulations were found to be between $7.20 \pm 0.185$ to $7.24 \pm 0.158$ that is within the range, which are presented in the table 4. Although alkaline, this $\mathrm{pH}$ is typical of creams containing borax and acceptable by the ISI standards.

\section{Viscosity}

Viscosities of all the formulations were noted and found in the range of $1256 \pm 6.24$ to $4897 \pm 7.52 \mathrm{CPS}$ at $10 \mathrm{rpm}$ as shown in table 4 . All the formulations were showed pseudo plastic flow.

\section{Spreadability}

The spreadability of all formulations was determined and it was observed that formulation FM5 has greater spreadability as compared to other formulations as well as the prototype formulation as shown in table 4.

\section{Thermal stability}

During storage and handling, cosmetic formulation's thermal stability, viscosity, and spreadability are the prime parameters which affect the formulation's acceptability. Amongst all of the formulations, formulations MF1, MF2, MF4, MF5, MF7 and MF8 showed better thermal stability at $20^{\circ} \mathrm{C}, 30{ }^{\circ} \mathrm{C}$ and $40{ }^{\circ} \mathrm{C}$. Based on the physicochemical parameters shown in table 4 and table 5 , less thermal stability and less spreadability resulted in cracking and phase separation of formulations (observed in MF3, MF6, and MF9).

Table 4: Thermal stability of all moisturizing cream formulations

\begin{tabular}{lll}
\hline Formulation code & Thermal stability* \\
\cline { 2 - 3 } & $\mathbf{2 0}{ }^{\circ} \mathbf{C}$ & $\mathbf{3 0}^{\circ} \mathbf{C}$ \\
\hline MF1 & $\mathrm{P}$ & $\mathrm{P}$ \\
MF2 & $\mathrm{P}$ & $\mathrm{P}$ \\
MF3 & $\mathrm{N}$ & $\mathrm{N}$ \\
MF4 & $\mathrm{P}$ & $\mathrm{P}$ \\
MF5 & $\mathrm{P}$ & $\mathrm{P}$ \\
MF6 & $\mathrm{N}$ & $\mathrm{P}$ \\
MF7 & $\mathrm{P}$ & $\mathrm{P}$ \\
MF8 & $\mathrm{P}$ & $\mathrm{P}$ \\
MF9 & $\mathrm{N}$ & $\mathrm{P}$ \\
Prototype formulation & $\mathrm{P}$ & $\mathrm{P}$ \\
\hline
\end{tabular}

*P-denotes stability of formulation, $\mathrm{N}$-denotes instability of formulation

Table 5: Evaluation parameters for the all moisturizing cream formulations

\begin{tabular}{lllll}
\hline Formulation code & pH (mean \pm SD) & Viscosity at 10 rpm (CPS) (mean \pm SD) & $\begin{array}{l}\text { Spreadability } \\
\text { (mean } \pm \text { SD) }\end{array}$ & $\begin{array}{l}\text { In vitro occlusivity* \% } \\
\text { (mean } \pm \text { SD) }\end{array}$ \\
\hline MF1 & $7.20 \pm 0.195$ & $1256 \pm 6.24$ & $5.00 \pm 0.10$ & - \\
MF2 & $7.22 \pm 0.152$ & $1459 \pm 6.58$ & $5.96 \pm 0.14$ & - \\
MF3 & $7.21 \pm 0.185$ & $1896 \pm 4.56$ & $4.72 \pm 0.10$ & - \\
MF4 & $7.20 \pm 0.189$ & $2089 \pm 5.89$ & $6.15 \pm 0.16$ & - \\
MF5 & $7.31 \pm 0.244$ & $2418 \pm 6.75$ & $6.95 \pm 0.10$ & $33.06 \pm 2.56$ \\
MF6 & $7.21 \pm 0.125$ & $3256 \pm 3.56$ & $5.76 \pm 0.19$ & - \\
MF7 & $7.22 \pm 0.174$ & $3546 \pm 7.85$ & $5.12 \pm 0.08$ & - \\
MF8 & $7.23 \pm 0.196$ & $4125 \pm 7.12$ & $5.40 \pm 0.16$ & - \\
MF9 & $7.24 \pm 0.158$ & $4897 \pm 7.52$ & $4.25 \pm 0.14$ & - \\
Prototype formulation & $7.22 \pm 0.148$ & $3502 \pm 6.95$ & $6.00 \pm 0.14$ & $29.49 \pm 2.85$ \\
\hline
\end{tabular}

*In vitro occlusivity test was determined for optimized formulation MF5 and prototype formulation for comparison, All values are mean \pm SD of three determinations. SD: Standard deviation 


\section{In vitro occlusivity test}

The weight loss of water (water flux) depends on the occlusivity of membrane offered by the formulations tested. The results of occlusivity are shown in the table 5 . When values were compared to that of uncovered filter and prototype formulation, MF5 showed significantly lower percentage of water loss than that both the formulations. The better occlusivity of sunflower wax creams could be attributed to the lipid nature of the developed formulations, preventing water evaporation to a greater extent. Occlusivity test indicates prevention of water loss. Higher the occlusivity more it prevents water loss from the system and lower the occlusivity less will be the capacity to prevent water loss. In case of moisturizing cream, humectants like propylene glycol, glycerin plays important role in retaining water in the skin. These humectants are water soluble where as liquid paraffin is oil in nature and its role is to form thin oily layer on the skin. Both these water phase and oil phase are brought together in emulsion form (cream) with the help of surface active agent. In the present formulation, stearic acid reacts with borax to form stearate which acts as a surfactant. Stearic acid is partially replaced by sunflower wax. This sunflower wax is consisting of higher fatty ester which hydrolyses in presence of borax to release higher fatty acid and higher fatty alcohol in situ. The fatty acid so formed reacts with borax to form surfactant and the higher fatty alcohol formed will provide emollient effect on the skin. It also improves spreadability of oily layer of liquid paraffin and the humectants play its natural role to prevent water loss. Thus overall occlusivity is improved by using sunflower wax in optimized formulation MF5 as compared to the prototype formulation as shown in table 5 .

\section{Particle size}

There is direct relationship between emulsion viscosity and the viscosity of the continuous phase. The viscosity of both $\mathrm{o} / \mathrm{w}$ and $\mathrm{w} / \mathrm{o}$ emulsions can be increased by reducing the particle size. The particle size of both optimized and prototype formulations were determined using Mastersizer 2000 indicates that optimized formulation MF5 have less particle size than standard formulation as a reduction in particle size of emulsion improves the viscosity of it and results in better emulsion stability. The results of particle size are shown in fig. 1 and fig. 2.

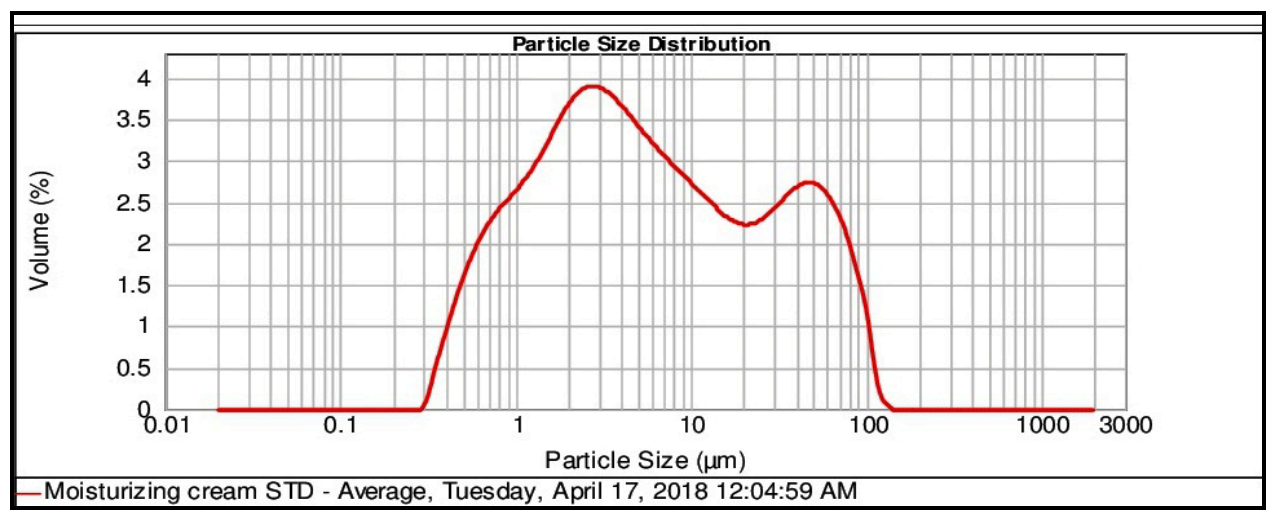

Fig. 1: Graph of particle size distribution for prototype formulation

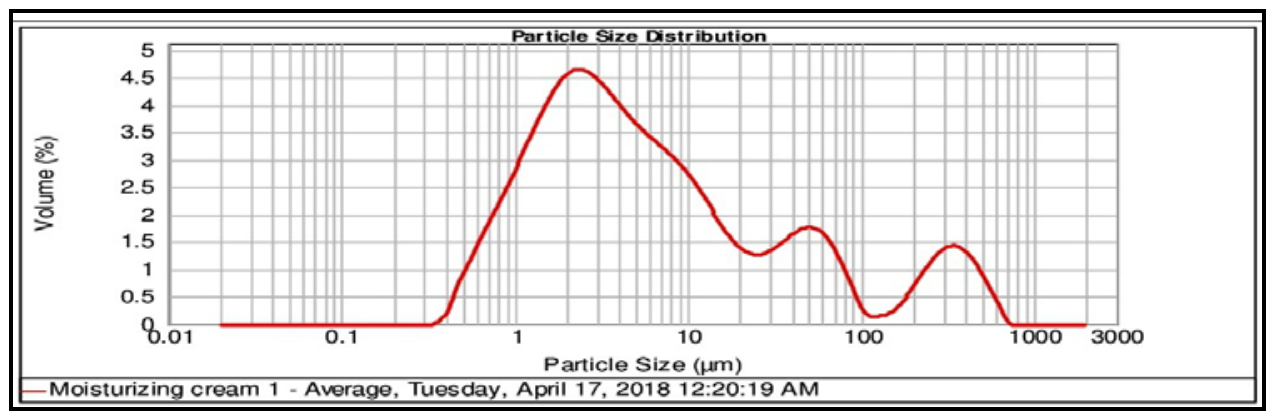

Fig. 2: Graph of particle size distribution for optimized formulation MF5

\section{Statistical analysis}

The purpose of using $3^{2}$ full factorial design was to conduct comprehensive study of effect of process parameters like stearic acid (X1) and sunflower wax (X2) and their interactions using a suitable statistical tool (Design expert software version 9.0.2.0) by applying one way ANNOVA at 0.05 levels. A mathematical modeling was carried out. Polynomial equation was obtained depending on significant influences among 2 factors on their experimental design.

\section{Response surface methodology}

The influence of main effects on responses was further elucidated by response surface methodology. It is widely used tool in the development and design of dosage form. The three dimensional response surface plot and corresponding two dimensional contour plots were generated by the software. The response surface plot is very useful for determination of main and interaction effects of the independent variables whereas two dimensional plots gives visual representation of values of responses. In case of viscosity the three dimensional response surface plot depicted the increase in viscosity as concentration of both variables increases. The two dimensional contour plot relating X1X2 (interaction between stearic acid and sunflower wax) was non linear indicating interaction between two variables. In case of spreadability the three dimensional response surface plot depicted the decrease in viscosity as concentration of both variables increases. Response surface plots are shown in fig. 3, 4 for viscosity and spreadability respectively. 


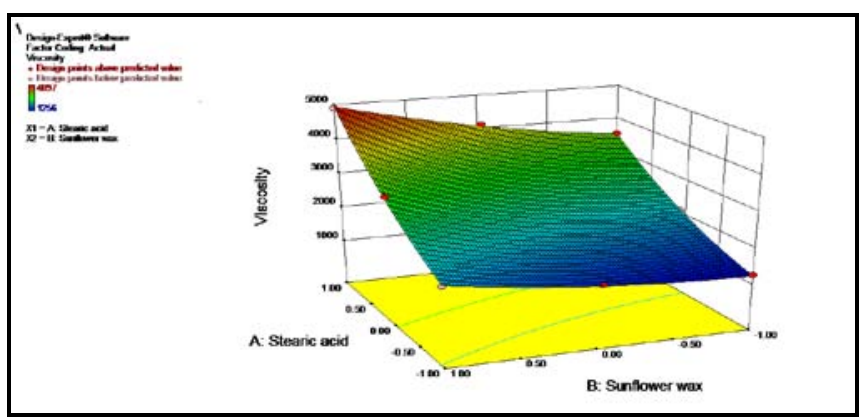

Fig. 3: Surface response plot showing effect of stearic acid and sunflower wax on viscosity

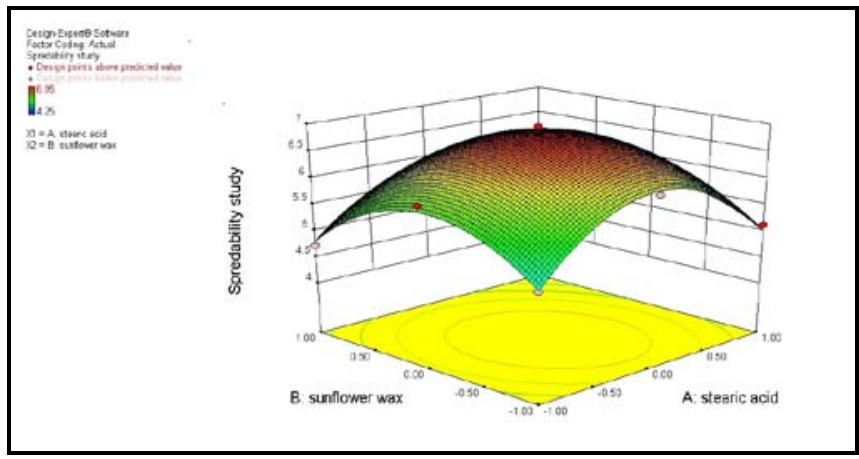

Fig. 4: Surface response plot showing effect of stearic acid and sunflower wax on spreadability

\section{Optimized formula}

After generating model equations relating main effects and responses, various cream formulations containing stearic acid and sunflower wax were optimized based on in vitro occlusivity (Y1), viscosity (Y2). The optimal values for responses were obtained by numerical analysis based on the criteria of desirability, and optimal batch was selected. Optimized batch was having optimal viscosity and highest spreadability. This reveals that mathematical model obtained by factorial design to produce optimized responses was well fitted.

\section{DISCUSSION}

Prepared moisturizing cream formulations were subjected to various assessment parameters and the findings obtained were within the limits which are depicted in table 4 and table 5. $\mathrm{pH}$ of all the formulations was found to be alkaline. All the formulations showed psuedoplastic flow on the basis of viscosity. The spreadability of formulation FM5 is greater as compared to other formulations as well as the prototype formulation. Amongst all of the formulations, only MF1, MF2, MF4, MF5, MF7 and MF8 showed better thermal stability at $20{ }^{\circ} \mathrm{C}, 30{ }^{\circ} \mathrm{C}$ and $40{ }^{\circ} \mathrm{C}$. The MF5 was selected as optimized formulation on the basis of results of spreadability and viscosity. The particle size of both optimized and prototype formulation indicates that reduction in particle size of emulsion improves the viscosity of it and results in better emulsion stability. In vitro occlusivity study was done for optimized formulation MF5 and prototype formulation. It is seen that overall occlusivity is improved by using sunflower wax in optimized formulation MF5 as compared to the prototype formulation.

\section{CONCLUSION}

The above studies show that moisturing creams containing a sunflower wax, despite its content of unsaponifiable matter, can be formulated with the aid of borax and ionic emulsifiers. The thermo physical behavior of the creams was found to be dependent on the proportion of sunflower wax relative to the emulsifiers. The cream formulation MF5 showed good in vitro occlusivity and spreadability and thus could be effective formulation to incorporate sunflower wax in the formulation, to avail of its cosmetic benefits. Study concludes that we are blessed with many of the magical natural ingredients, it depends upon us to explore them scientifically to treat skin related problems. Formulators must play an active role to replace stearic acid from the dermato-cosmetic products so that consumers can get the maximum benefits of our traditional heritage. It is anticipated, this work will kindle more research and faith towards utilization of natural active ingredients in the cosmetics.

\section{ACKNOWLEDGMENT}

The authors are thankful to M/s Mahesh Ltd., Mumbai, India for providing gift sample of sunflower wax. Authors are delighted to say thank you to the Principal and management of Maulana Azad Educational Trust's Y. B. Chavan College of Pharmacy, Aurangabad, MS, India. For support and providing necessary facilities to carry out the research work successfully. Authors are also thankful to Prof. Vandana B. Patravale for providing necessary technical and moral support.

\section{AUTHORS CONTRIBUTIONS}

Experimental design, guidance, supervision and review work for the research was done by Dr. Swaroop R. Lahoti. Experimental work, development and optimization of the formulations, interpretation of result and writing of this manuscript was done by Mr. Avish D. Maru. Both authors read and approve the final manuscript.

\section{CONFLICT OF INTERESTS}

All authors have none to declare

\section{REFERENCES}

1. Rawlings $A V$, Harding CR. Moisturization and skin barrier function. Dermatol Ther 2004;17:43-8.

2. Marty JP. NMF and cosmetology of cutaneous hydration. Ann Dermatol Venereol 2002;129:131-6.

3. Cravellol B, Ferri A. Relationships between skin properties and environmental parameters. Skin Res Tech 2008;14:180-6.

4. Thorleifsson A, Wulf HC. Emollients and the response of facial skin to a cold environment. Br J Dermatol 2003;148:1149-52.

5. Egawa M, Oguri M, Kuwahara T. Effect of exposure of human skin to a dry environment. Skin Res Tech 2002;8:212-8. 
6. Flynn TC, Petros J, Clark RE. Dry skin and moisturizers. Clin Dermatol 2001;19:387-92.

7. Yosipovitch G. Dry skin and impairment of barrier function associated with itch-new insights. Int J Cosm Sci 2004;26:1-7.

8. Loden M. Biophysical methods of providing objective documentation of the effects of moisturizing creams. Skin Res Technol 1995;1:101-8.

9. Awlings AVR, Anestrari DAC, Dobkowski B. Moisturizer technology versus clinical performance. Dermatol Ther 2004;17:49-6.

10. Kapoor S, Saraf S. Risk analysis tools for toxicological profile of cosmetics. Int J Toxicol 2008;5:1-20.

11. Paul Cancalon, Chemical composition of sunflower seed hulls. J Am Oil Chem Soc 1971;486:29-32.

12. Morrison WH. Variation in the wax content of sunflower seeds with location and hybrids. J Am Oil Chem Soc 1983;60:1013-5.

13. Ramos Ayerbe. A study on the recovery of byproducts from the dewaxing of sunflower oils of national production. Grasas Aceites 1985;36:1-4.

14. Wannee J. Review of nutraceutical uses of an antioxidant sunflower sprout. Asian J Pharm Clin Res 2016;9:21-3.

15. Mariani C. Minor components of vegetable oils: non-glyceridic esters. Riv Ital Sostanze Grasse 1989;66:397-401.

16. Amalia A Carelli. Wax composition of sunflower seed oils. J Am Oil Chem Soc 2002;79:763-8.

17. PP Sharma. Cosmetics-formulation, manufacturing and quality control, Cap. VII. 5th edition Vandana Publications, Delhi, India; 2014. p. 181-91.
18. Lachman $\mathrm{L}$, Herbert $\mathrm{AL}$, Joseph LK. The theory and practice of industrial pharmacy. Chp III. Varghese Publication House, India; 1999. p. 569.

19. Indian Standard Bureau IS: 6608; 1978. p. 5.1-6.1.

20. Indian Standard Bureau. Methods of testing for safety evaluation of cosmetic; 1997.

21. Julie MJ, Athira A, Verjina $\mathrm{Cu}$, Vasudevan DT, Saritha AS, Formulation and evaluation of antiaging phytosomal gel. Asian J Pharm Clin Res 2018;11:409-22.

22. Mandawgade SD, Patravale VB. Development of SLNs from natural lipids: application to topical delivery of tretinoin. Int J Pharm 2008;363:132-8.

23. Rowe RC, Sheskey PJ, Weller PJ. Handbook of pharmaceutical excipients. London: Pharmaceutical Press; 2003.

24. Dua D, Srivastava NS. Study on antioxidant and anti-aging properties of few medicinal plants. Int J Pharm Pharm Sci 2016;8:344-7.

25. Taylor P. Ostwald ripening in emulsions. Adv Colloid Interface Sci 1998;75:107-63.

26. Baird. Analysis of creams and lotions. In: Henry MD. editor. Manual of cosmetic analysis. USA; 1997. p. 32-3.

27. Clarke MT. Rheological additives. In: Laba D. editor. Rheological properties of cosmetic and toiletries. New York: Marcel Dekker 1993. p. 55-152.

28. Multimer M. Spreadability determination by an apparatus. J Am Pharm Assoc 1956;45:212-4. 